Letter to the Editor

\title{
Measles and Brugada pattern: A case report
}

\author{
G. Coppola, G. Dendramis *, E. Corrado, C. Paleologo, G. Ciaramitaro, P. Assennato, S. Novo \\ U.O.C. di Cardiologia II con Emodinamica, Scuola di Specializzazione in Malattie dell' Apparato Cardiovascolare, A.O.U.P. “P. Giaccone”, Università degli Studi di Palermo, Italy
}

\section{A R T I C L E I N F O}

\section{Article history:}

Received 5 October 2012

Accepted 29 October 2012

Available online 14 November 2012

\section{Keywords:}

Brugada syndrome

Measles

Sudden cardiac death

\section{Introduction}

Brugada syndrome is an autosomal dominant arrhythmogenic disease with incomplete penetrance due, in $25-30 \%$ of cases, to an alteration sodium channel, secondary to a mutation of SCN5A gene; from the electrocardiographic point of view is characterized by an elevation of the ST segment in right precordial leads V1 to V3 with a QRS morphology similar to a right bundle branch block. The isolated presence of that electrocardiographic pattern does not constitute a high risk of sudden cardiac death, but poses several problems in the order to the quantification of the same and for the type of follow-up to be established for these patients [1].

\section{Case report}

A healthy 31-year-old male, with no cardiovascular risk factors and no relevant clinical history, was referred to our department for symptoms characterized by intermittent fever, cough, and chest pain for about 5 days and resistant to therapy with paracetamol, corticosteroids and antibiotics.

The blood sample showed leukopenia and increase the indices of inflammation. The patient was subjected to hematological advice, abdominal ultrasound, chest radiography and chest computed tomography, investigations being all normal.

The ECG performed in emergency room showed a right bundle branch block with ST-segment elevation in V1-V2 and for the persistence of chest pain a cardiology consult in emergency was requested, in which blood pressure was found normal $(110 / 70 \mathrm{~mm} \mathrm{Hg})$ and

\footnotetext{
* Corresponding author. Tel.: +039 1 6554303; fax: +039 16554304.

E-mail address: gregorydendramis@libero.it (G. Dendramis).
}

manifested fever $\left(39.5^{\circ} \mathrm{C}\right)$.The ECG showed sinus tachycardia and Brugada pattern "coved" type (Fig. 1). The echocardiogram was normal. The history of syncope or family history of sudden death was negative. He underwent anti-inflammatory drug therapy with high dose of paracetamol and at the defervescence of fever, in conjunction with the regression of chest pain, the ECG control was within limits (Fig. 2). The patient was admitted to an operative unit of medicine where, in the next day, punctiform rash spread to the face, trunk and thighs and diagnosing of measles was performed; the body temperature was $37.7^{\circ} \mathrm{C}$. The ECG monitoring did not show Brugada pattern. In consideration of the ECG and the risk profile, according with the current Consensus Report on the Brugada syndrome [3,4], it was decided not to submit the patient to further investigation, but to a close follow-up. Currently scientific evidence indicates in these patients that it is important to check serum electrolytes and perform periodic ECG, Holter, counteract effectively fever and avoid certain drugs that are arrhythmogenic or with negative effect on the electrical fault of the disease.

\section{Conclusions}

Scientific evidence now indicates that in patients with Brugada syndrome, and in patients with a spontaneous type 1 ECG with no history of syncope and without familiarity (Brugada type pattern), it is important to check serum electrolytes such as magnesium, potassium, calcium, sodium, chlorine, and make periodic ECG and Holter monitoring. During any flu syndrome, fever is an element to be monitored immediately at the onset with adequate treatment of pyrexia [2].

On the basis of clinical evidence, in patients suffering from Brugada syndrome or pattern-like Brugada, should strictly avoid taking certain medications such as many antiarrhythmics, psychotropics, anesthetics, analgesics, and alcohol abuse, since they have arrhythmogenic effect or with negative effect on the electrical fault of the disease [3].

The previous history of syncope is the most important indicator for a poor prognosis. In the presence of a spontaneous diagnostic ECG, associated with a history of syncope, the implantation of a defibrillator in primary prevention is therefore justified [5]. The therapeutic procedure is complicated in the case in which we are dealing with a patient with a spontaneous type 1 ECG with no history of syncope and no family history, just as in the case report presented.

In the largest cohort of patients with Brugada syndrome so far studied (FINGER Brugada Syndrome Registry) [1], the risk of arrhythmic events was low in asymptomatic patients (prevalence $0.5 \%$ ). The presence of syncopal events, cardiac arrest and type 1 electrocardiographic pattern was the only independent predictor of arrhythmic events. However, today, it is not possible to identify with absolute 


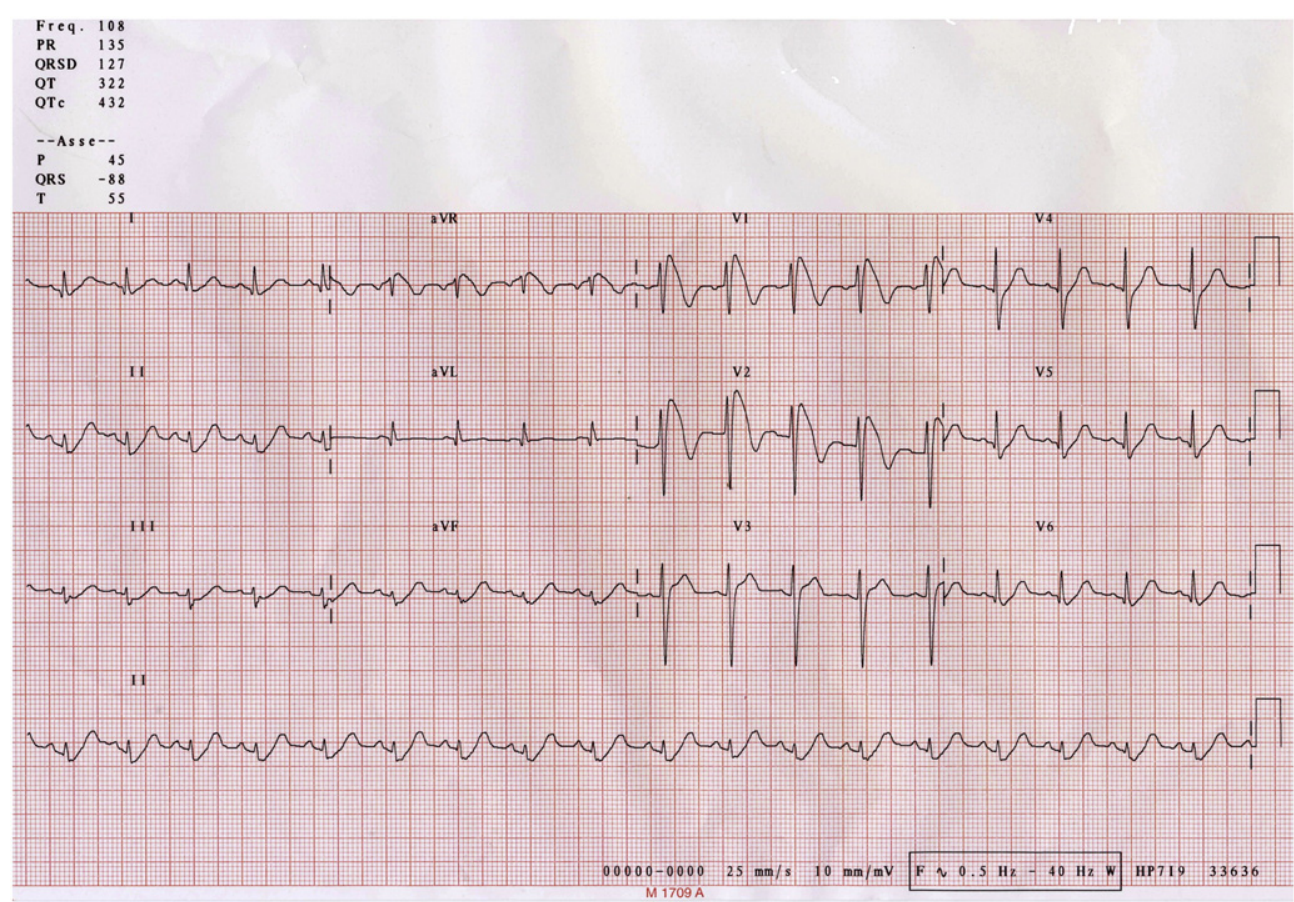

Fig. 1. ECG at the admission with sinus tachycardia and coved type Brugada pattern in conjunction with temperature increasing $\left(39.5{ }^{\circ} \mathrm{C}\right)$.

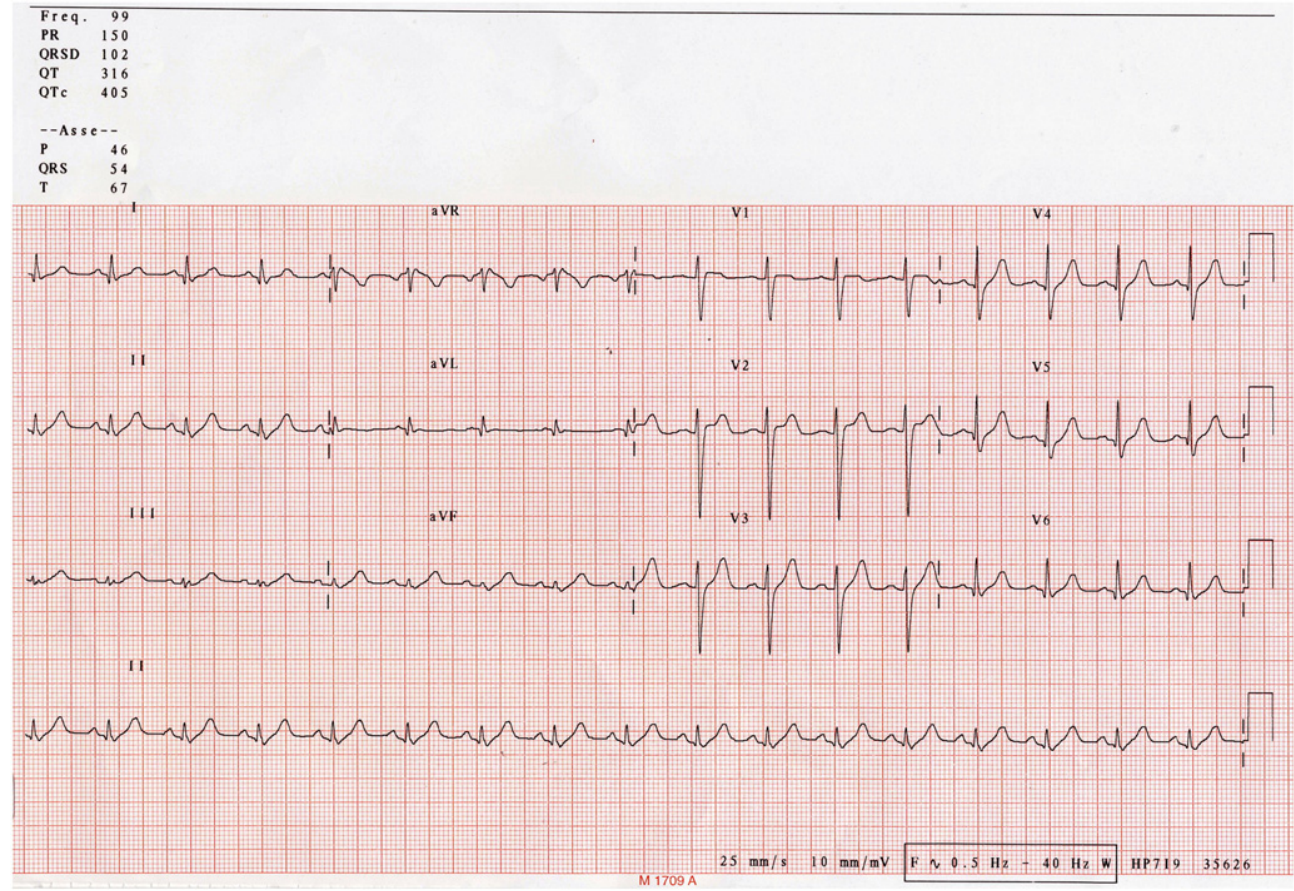

Fig. 2. ECG during defervescence.

certainty a uniform and shared behavior about the duration and type of follow-up for all those patients with similar characteristics to those presented by us.

\section{References}

[1] Probst V, Veltmann C, Eckardt L, et al. Long-term prognosis of patients diagnosed with Brugada syndrome: results from the FINGER Brugada Syndrome Registry. Circulation 2010;121:635-43.
[2] Patanè S, Marte F, La Rosa FC, et al. Revelation of Brugada electrocardiographic pattern during a febrile state. Int J Cardiol Apr 1 2010;140(1):e19-21.

[3] Antzelevitch C. Brugada syndrome. Pacing Clin Electrophysiol 2006;29:1130-59.

[4] Antzelevitch C, Brugada P, Borggrefe M, et al. Brugada syndrome: report of the second consensus conference: endorsed by the Heart Rhythm Society and the European Heart Rhythm Association. Circulation 2005;111:659-70.

[5] Brugada J, Brugada R, Brugada P. Determinants of sudden cardiac death in individuals with the electrocardiographic pattern of Brugada syndrome and no previous cardiac arrest. Circulation 2003;108:3092-6. 